\title{
The photo-physiologica inhibited mechanism on typical HABs,Scrippsiella trochoidea, by seawater extraction of macroalga, Gracilaria Lemaniformis
}

\author{
Changpeng Ye, Ruoyang Chen and Jiangang Zhao
}

Institute of Hydrobiology, Jinan University, Key Laboratory of Eutrophication and Red Tide Control, Education Department of Guangdong Province, Guangzhou 510632, Guangdong Province, China.

E-Mail: tcpyes@jnu.edu.cn

Keywords: eutrophication, macroalga, Hamful algal blooms (HABs), photophysiological activity, allelopathic effect.

Abstract. Macroalga, due to its high-harvesting yield, easily available, low-cost, and eco-friendly, become more and more favored tool-like alga for researchers. The method of control harmful algal blooms (HABs) by macroalga is an international study issue, and the water extract of seaweed have the advantage of full-time and all-location. While the most study were focused on the level of apparent growth, little was known about the photo-physiological inhibited mechanism in HABs by macroalga. In this study, the thecate dinoflagellate bloom microalga, Scrippsiella trochoidea, was co-cultured with different grams seawater extraction from fresh macroalga Gracilaria lemaneiformis under laboratory conditions photosynthetic oxygen evolution and Chlorophyll fluorescence techniques are used, to study the effects of the seawater extract of Gracilaria lemaneiformis on the photosystem II (PS II ) of red tide algae. The results are as follows: Compared with control, the biomass of $S$. trochoideain $0.6 \mathrm{~g} / \mathrm{L}$ treatment was higher, while the biomass in $1.2 \mathrm{~g} / \mathrm{L}, 2.4 \mathrm{~g} / \mathrm{L}$ and $4.8 \mathrm{~g} / \mathrm{L}$ treatment are lower, which shows the pattern of hormesis effect. Photosynthetic oxygen evolution rates $\left(P_{\max }\right)$ were decreased with the increase of extract concentration, while the dark respiration rates $(R d)$ were converse. The $\mathrm{J}, \mathrm{I}, \mathrm{P}$ points in $0.6 \mathrm{~g} / \mathrm{L}$ treatment were higher than the control one, while J, I, P points in $1.2 \mathrm{~g} / \mathrm{L}$ treatment is lower. OJIP curve in $2.4 \mathrm{~g} / \mathrm{L}$ and $4.8 \mathrm{~g} / \mathrm{L}$ tend to be a straight line. The value of $\mathrm{Wk}, \mathrm{ABC} / \mathrm{RC}, \mathrm{TRo} / \mathrm{RC}, \mathrm{DIo} / \mathrm{RC}, \mathrm{Vj}, \varphi \mathrm{Do}$ and Mo in $2.4 \mathrm{~g} / \mathrm{L}$ and $4.8 \mathrm{~g} / \mathrm{L}$ treatments was increased, while the value of fraction of OEC, $\varphi \mathrm{Po}, \mathrm{Fv} / \mathrm{Fo}, \mathrm{ETo} / \mathrm{RC}, \psi 0$, and $\varphi$ Eo was decreased.

The inhibitory effects of the macroalga's sea water extraction on the microalga, according to the JIP-test and pigments contents, include a decrease in the number of active reaction centers, the blocking-up of the electron transport chain. This study suggests that water extraction of $G$. lemaneiformis is effective in inhibiting photophysiological activity of $S$. trochoidea, and thus be a potential 'tool alga' for controlling $S$. trochoidea blooms.

\section{Introduction}

Worldwidely, nitrogen and phosphorus loading from industrial, agricultural and municipal sources accelerates eutrophication in coastal areas ${ }^{1}$. Eutrophication may lead to explosive growth of phytoplankton including harmful algal blooms (HABs), which have significant detrimental effects on fishery resources, marine ecosystems and human health globally ${ }^{2,3}$. Climate-induced changes can also act synergistically with anthropogenic nutrient enrichment to increase harmful algal bloom frequency and geographical extent ${ }^{4,5}$. A cosmopolitan species, Scrippsiella trochoidea (Stein) Loeblich III, is distributed mainly in neritic habitats from the tropical to cold-temperate seas ${ }^{6,7,8}$. Formerly deemed as a non-toxic species, $S$. trochoidea is a thecate dinoflagellate bloom microalga reported from Japan, Korea and China ${ }^{9,10}$, and was reported recently also as a toxic species responsible for killing larvae of bivalve species ${ }^{11}$. In bloom conditions in the field, $S$. trochoidea was observed to produce smooth and calcareous or non-calcified cysts ${ }^{8}$. Wild and cultured fish and shellfish kills have been reported to be associated with blooms of S. trochoidea in Australia ${ }^{12}$ and China ${ }^{13}$. 
Therefore, there is a need to develop management and mitigation strategies to control HABs. Various physical methods, inculding light-shading and solar ultraviolet radiation ${ }^{14,15}$, and chemical strategies ${ }^{16,17}$ have been applied. However, the large-scale application of these methods is limited by high cost and the potential for ecological secondary pollution ${ }^{18,19}$. In contrast, biological controls using macroalgae such as Ulva pertusa and Gracilaria species are found to mitigate HABs effectively. These species are indigenous to the marine environment, easy to collect, low cost and environmentally friend ${ }^{20-22}$.

G. lemaneiformis, an edible red alga broadly distributed and intensively cultivated in the coastal areas of China, is an economically important alga for agar extraction ${ }^{23}$ and extraction of other natural products with important bioactivity ${ }^{24,25}$, and is also used as a food addictive in aquaculture ${ }^{26}$. It has been shown that $G$. lemaneiformis and other macroalgae have an inhibitory effect on the growth of some HAB species whether they are used as fresh thalli, culture filtrate, water-soluble extract or dry powder ${ }^{27-29}$. These macroalgae can therefore mitigate the negative effects of HABs by varying the make up of the phytoplankton community, changing the dominant species and decreasing microalgal abundance $^{30}$.

Despite a number of studies on growth of HABs, the photosynthetic inhibitory mechanisms by which seaweed extraction may affect HABs remains unconfirmed. In this study, the inhibition of $S$. trochoidea photosynthesis by G. Lemaneiformis extraction is characterized. As photosynthesis is the primitive driving force of physiological and biochemical processes in photoautotrophs, characterizing the photobiological profile provides useful information about the mechanisms by which $G$. lemaneiformi extraction acts as a potential algicide souse against blooms of $S$. trochoidea.

\section{Materials and methods}

\section{Culture of the seaweed}

Fresh thalli of Gracilaria lemaneiformis were collected in April 2011 from the Nanao Island Cultivation Zone $\left(116.6^{\circ} \mathrm{E}, 23.3^{\circ} \mathrm{N}\right)$, Shantou, Guangdong, China. Thalli were transported in $500 \mathrm{~mL}$ sterile bottles filled with sterile seawater (SSW) to the laboratory where they were rinsed thoroughly with $100 \mathrm{~mL} \mathrm{SSW}$ and treated with a mixture of penicillin, chloramphenicol, polymixin and neomycin at non-inhibiting concentrations after $\mathrm{Nakai}^{31}$ and Jeong ${ }^{32}$. The medium used for algal cultivation was prepared according to the method of $\operatorname{Jin}^{20}$. The $\mathrm{pH}$ and salinity were adjusted to 8.0 and $30 \%$, respectively. Treated thalli were placed in sterile bottles containing SSW and were allowed to adapt to the laboratory environment for $5 \mathrm{~d}$ before use in experiments. Nutrients were enriched in the culture medium weekly by adding $100 \mu \mathrm{mol} \mathrm{L}{ }^{-1}$ of $\mathrm{NaNO}_{3}$ and $7 \mu \mathrm{mol} \mathrm{L}{ }^{-1}$ of $\mathrm{NaH}_{2} \mathrm{PO}_{4}$. Nutrient enrichment was stopped 1 week before the experiments. The temperature was kept at $20 \pm 0.1{ }^{\circ} \mathrm{C}$ on a $12: 12$ light:dark cycle. Illumination was provided by cool-white fluorescent lamps at $70 \mu \mathrm{mol}$ photons $\mathrm{m}^{-2}$ $\mathrm{s}^{-1}$. G. lemaneiformis fresh thalli were always maintained axenically under laboratory conditions and the effect of the environmental bacteria was considered negligible.

\section{Preparation of maxroalgal water extraction}

Surface precipitation of salt on the thalli of macroalga was washed, then naturally airedr to constant weight at room temperature, ground with mortar, screened by 80 mesh. 15 g dry powder was extracted with sterilized in table concentrator at room temperature. The exraction was collected daily upto three days, then the collector was dried in rotary evaporators, volumed to $100 \mathrm{ml}$ with sterilized sea wate.r 150 PPT extraction was prepared. The extraction was filtered by 0.22 um cellulose acetate membrane to remove the G. lemaneiformis slag and some microbes in the leached solution, the filtrate was put in the refrigerator $\left(4{ }^{\circ} \mathrm{C}\right)$ for future use..

\section{Culture of Microalga}

S. trochoidea was cultured in modified $\mathrm{f} / 2$ medium $^{48}$ at $20^{\circ} \mathrm{C}, 70 \mu \mathrm{mol} \mathrm{m} \mathrm{m}^{-2} \mathrm{~s}^{-1}$ under a $12 \mathrm{~h}: 12 \mathrm{~h} \mathrm{LD}$ cycle. The initial $\mathrm{pH}$ and salinity of the culture medium were adjusted to $8.0 \pm 0.02$ and $30 \%$, respectively. The flask containing microalga was shaken manually twice daily, and grown to exponential phase for use in the experiments. Cells were inoculated into $500 \mathrm{~mL}$ Erlenmeyer flasks 
containing fresh $\mathrm{f} / 2$-enriched seawater until the total volume was $300 \mathrm{~mL}$. The initial cell density was $1.0 \times 10^{4}$ cells $\mathrm{mL}^{-1}$. The microalgal culture (monoculture) was used as a control throughout the experiment.

\section{Experiments with microalga and sea water extraction of G. lemaneiformis}

The stock sea water extraction of G. lemaneiformis was diluted to $0.6 \mathrm{~g} / \mathrm{L}, 1.2 \mathrm{~g} / \mathrm{L}, 2.4 \mathrm{~g} / \mathrm{L}$ and $4.8 \mathrm{~g} / \mathrm{L}$, exponentially growing microalgae was inoculated with the above diltued extratction at the same time in the culture medium. Monoculture with only S. trochoidea was served as the control. Three replicates were prepared for each experiment, and experiments were monitored for 4 days.

\section{Measurement of chlorophyll fluorescence}

Every other day, Chl $a$ fluorescence transients of $S$. trochoidea were measured at room temperature using a plant efficiency analyser (PEA, Hansatech Instruments, Norfolk, England) with an actinic light of $3000 \mu \mathrm{mol}$ photon $\mathrm{m}^{-2} \mathrm{~s}^{-1} 33$. Illumination was provided by an array of six high-intensity light-emitting diodes (with a peak wavelength of $650 \mathrm{~nm}$ ), which were focused on the sample surface to provide homogeneous illumination over an area of $4 \mathrm{~mm}$ in diameter. All samples were dark-adapted for $15 \mathrm{~min}$ before measurement. The whole experiment lasted for 9 days.

The fluorescence intensities at $50 \mu \mathrm{s}, 300 \mu \mathrm{s}$ (K-step), $2 \mathrm{~ms}$ (J-step) and $30 \mathrm{~ms}$ (I-step) were denoted as $F_{0}, F_{300} \mu \mathrm{s}, F_{\mathrm{J}}$ and $F_{\mathrm{I}}$, respectively, and $\mathrm{F}_{\mathrm{m}}$ was assumed as the maximum fluorescence intensity ${ }^{33}$. The specific parameters were calculated according to the JIP-test ${ }^{34}$. To carry out the JIP test, several extracted and technical fluorescence parameters calculated from the measurements of the polyphasic fluorescence transients are needed. They are: (1) the minimal fluorescence yield, $F_{0}$ (the fluorescence intensities when all reaction centers are open), (2) the maximal fluorescence yield, $F_{\mathrm{m}}$ (the excitation intensity is high enough to ensure the closure of all reaction centers), (3) the initial slope at the beginning of the variable fluorescence transients theoretically at time zero), $\mathrm{dV} / \mathrm{dt}_{0}$ $\left[=4\left(F_{300} \mu \mathrm{s}-F_{0}\right) /\left(F_{\mathrm{m}}-F_{0}\right)\right]$; and (4) the relative variable fluorescence at phase $\mathrm{J}, V_{\mathrm{J}}\left[=\left(F_{\mathrm{J}}-F_{0}\right) /\left(F_{\mathrm{m}}-F_{0}\right)\right]$. According to the JIP test, the energy flux for absorption (ABS), energy flux for trapping (TR) and enegry flux for electron transport (ET) per photosystem II (PSII) reaction center (RC) are given by equations 1-3, respectively. The concentration of the PSII reaction centers (RC/CS, indicating the density of active reaction center, i.e. photosynthetic units) are is given by equation 4 or 9 and 10 . Specific fluxes or specific activities of photosystem:

$$
\begin{gathered}
\mathrm{ABS} / \mathrm{RC}=\left[\left(d V / d t_{0}\right) / V_{\mathrm{J}}\right] /\left[1-\left(F_{0} / F_{\mathrm{m}}\right)\right] \\
\mathrm{TR}_{0} / \mathrm{RC}=\left(d V / d t_{0}\right) / V_{\mathrm{J}} \\
\mathrm{ET}_{0} / \mathrm{RC}=\left[\left(d V / d t_{0}\right) / V_{\mathrm{J}}\right] \cdot\left(1-V_{\mathrm{J}}\right) \\
\text { Density of reaction centrescenters: } \\
\mathrm{RC} / \mathrm{CS}=\left[V_{\mathrm{J}} /\left(d V / \mathrm{d} t_{0}\right)\right] \cdot\left[1-\left(F_{0} / F_{\mathrm{m}}\right)\right] \cdot F_{0} \\
\text { Quantum efficiencies or flux ratios: } \\
\varphi_{P o}=\mathrm{TR}_{0} / \mathrm{ABS}=1-\left(F_{0} / F_{\mathrm{m}}\right)=F_{\mathrm{v}} / F_{\mathrm{m}} \\
\psi_{0}=\mathrm{ET}_{0} / \mathrm{TR}_{0}=\left(1-V_{\mathrm{J}}\right)
\end{gathered}
$$

Phenomenological fluxes or phenomenological activities:

$$
\begin{aligned}
& \mathrm{ABS} / \mathrm{CS}_{0} \approx F_{0} \\
& \mathrm{RC} / \mathrm{CS}_{0}=\varphi_{\mathrm{Po}} \cdot\left(V_{\mathrm{J}} / F_{0}\right) \cdot\left(\mathrm{ABS} / \mathrm{CS}_{0}\right) \\
& \mathrm{TR}_{0} / \mathrm{CS}_{0}=\varphi_{\mathrm{Po}} \cdot\left(\mathrm{ABS} / \mathrm{CS}_{0}\right) \\
& \mathrm{ET}_{0} / \mathrm{CS}_{0}=\varphi \mathrm{E}_{\mathrm{o}} \cdot\left(\mathrm{ABS} / \mathrm{CS}_{0}\right)
\end{aligned}
$$

Where $\mathrm{ABS} / \mathrm{CS}_{0}$ represents absorption flux per excited cross-section of sample (at $\mathrm{t}=0$ ), indicating the quantity of antenna chlorophyll; $\mathrm{RC} / \mathrm{CS}_{0}$, the amount of active PSII reaction centers per excited cross-section $\left(\right.$ at $\left.\mathrm{t}=\mathrm{t}_{\mathrm{F} 0}\right) . \mathrm{TR}_{0} / \mathrm{CS}_{0}$, the trapping flux per excited cross sectionat at $\mathrm{t}=0 ; \mathrm{ET}_{0} / \mathrm{CS}_{0}$, the electron transport flux per excited cross sectionat at $\mathrm{t}=0$.

\section{Determination of Chl a and carotenoid}

Every other day, the sample of $S$. trochoidea was collected in a $15 \mathrm{ml}$ tube and centrifuged for 10 min at $5000 \mathrm{rpm}$ at $20^{\circ} \mathrm{C}$ in the high speed freezing centrifuge (5810R, Eppendorf, Germany). The sediment was extracted in $4 \mathrm{ml}$ absolute methanol for $24 \mathrm{~h}$ at $4^{\circ} \mathrm{C}$ in the dark. This extract was centrifuged at $5000 \mathrm{rpm}$ for $10 \mathrm{~min}$ and analyzed for Chl $a$ and carotenoid content with a scanning 
spectrophotometer (UV 530, Beckman Coulter, USA). The Chl $a$ and carotenoid concentration was calculated according to Wellburn ${ }^{35}$.

\section{Data statistical analysis}

Data were analyzed by two-way ANOVA followed by a multiple comparison using the least significance difference (LSD) test. Calculations and statistical analyses were performed with SPSS 13.0 for Windows. $P$-values of 0.05 were considered as a significant.

\section{Results and Discussion}

\section{Results}

Compared with control, the biomass (shown as chlorophyll a concentration) of S. trochoideain $0.6 \mathrm{~g} / \mathrm{L}$ treatment was higher, while the biomass in $1.2 \mathrm{~g} / \mathrm{L}, 2.4 \mathrm{~g} / \mathrm{L}$ and $4.8 \mathrm{~g} / \mathrm{L}$ treatment are lower, which shows the pattern of hormesis effect (Fig. 1).

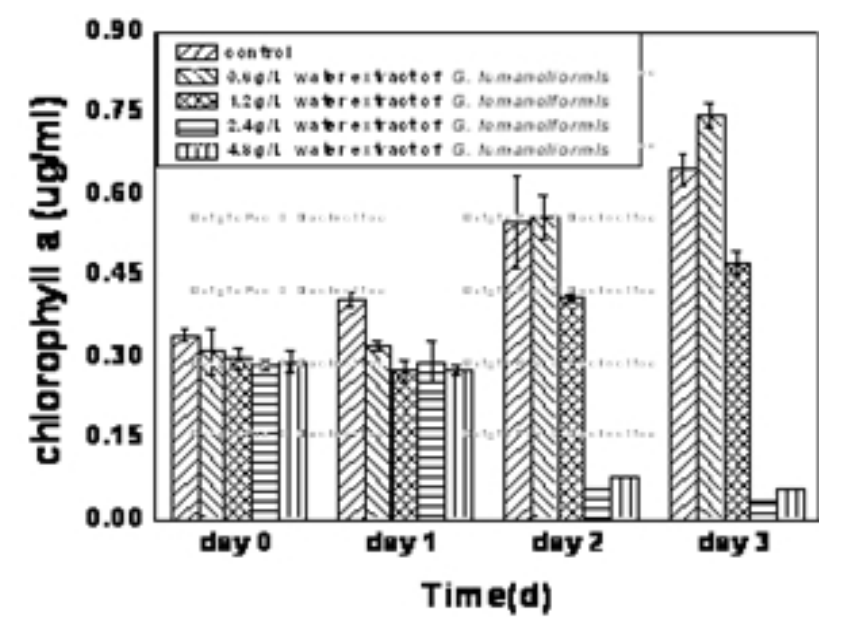

Fig.1. Chlorophyll $a$ contents of S. trochoidea cultured with different concentrations of the water extract of G. lemaneiformis
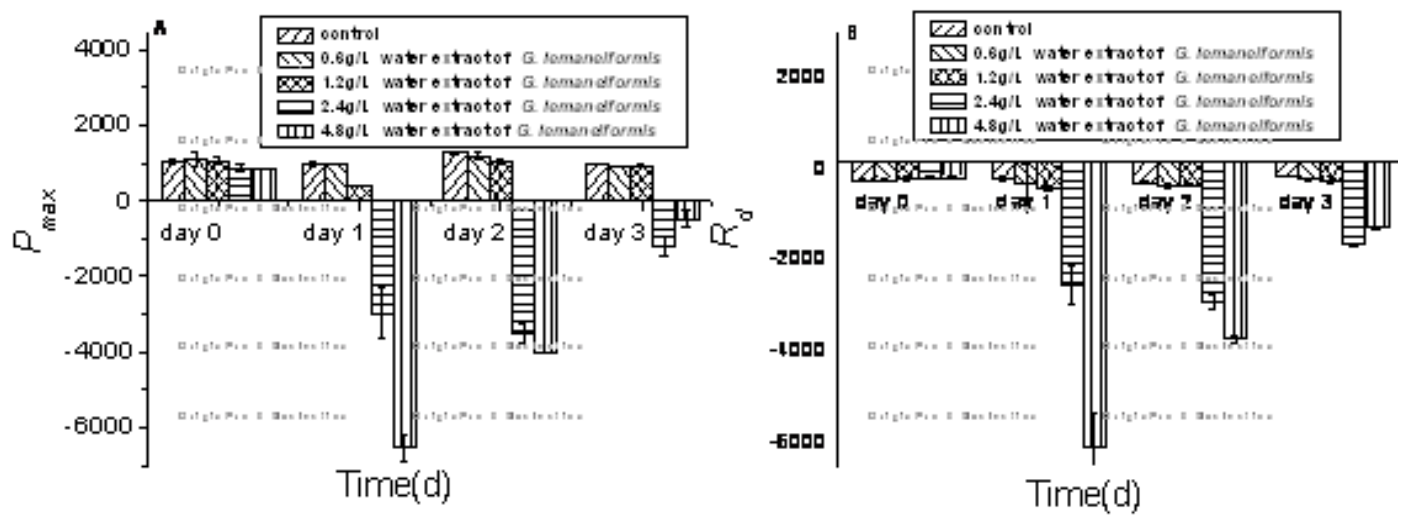

Fig.2. The maximum photosynthetic oxygen evolution rate $\left(P_{\max }\right)$ of $S$. Trochoidea (A) and dark respiration rate ( $R d$ ) $S$. Trochoidea (B)cultured with different concentrations of the water extract of G.lemaneiformis 
Photosynthetic oxygen evolution rates $\left(P_{\max }\right)$ were decreased with the increase of extract concentration, while the dark respiration rates $(R d)$ were converse (Fig. 2).
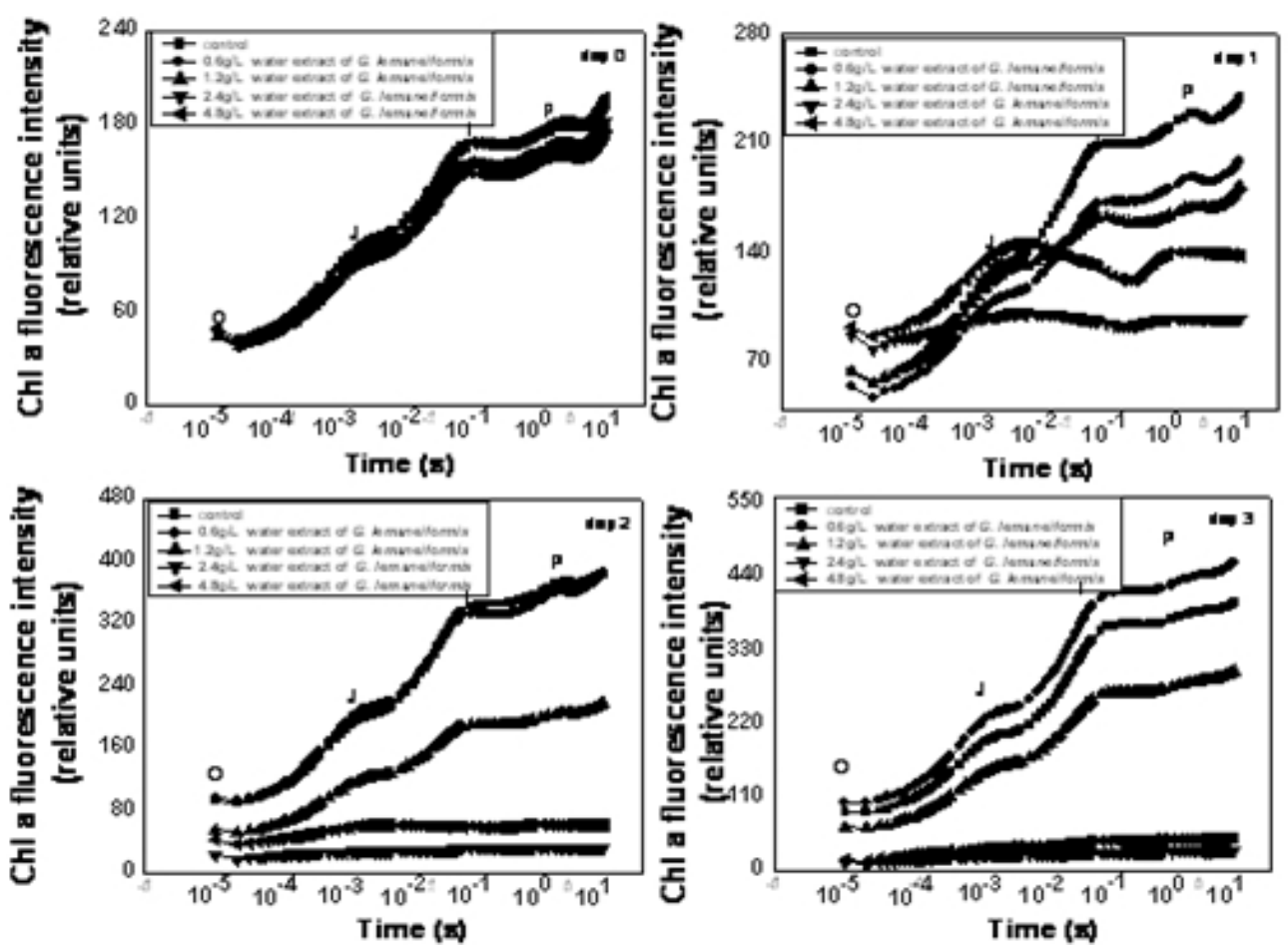

Fig.3 The O-J-I-P curves of S. Trochoidea co-cultured with different concentrations of the water extract of G. lemaneiformis

Figure 3 shows fluorescence induction curves for dark-adapted samples. The addition of water extraction of $G$. lemaneiformis lowered the polyphasic chlorophyll fluorescence transients (OJIP) intensities of $S$. trochoidea during the whole experiment period, with a positive correlation between the amount of extraction added and the amount of inhibition (Fig. 3).

The J, I, P points in $0.6 \mathrm{~g} / \mathrm{L}$ treatment were higher than the control one, while J, I, P points in $1.2 \mathrm{~g} / \mathrm{L}$ treatment is lower. OJIP curve in $2.4 \mathrm{~g} / \mathrm{L}$ and $4.8 \mathrm{~g} / \mathrm{L}$ tend to be a straight line (Fig. 3). 

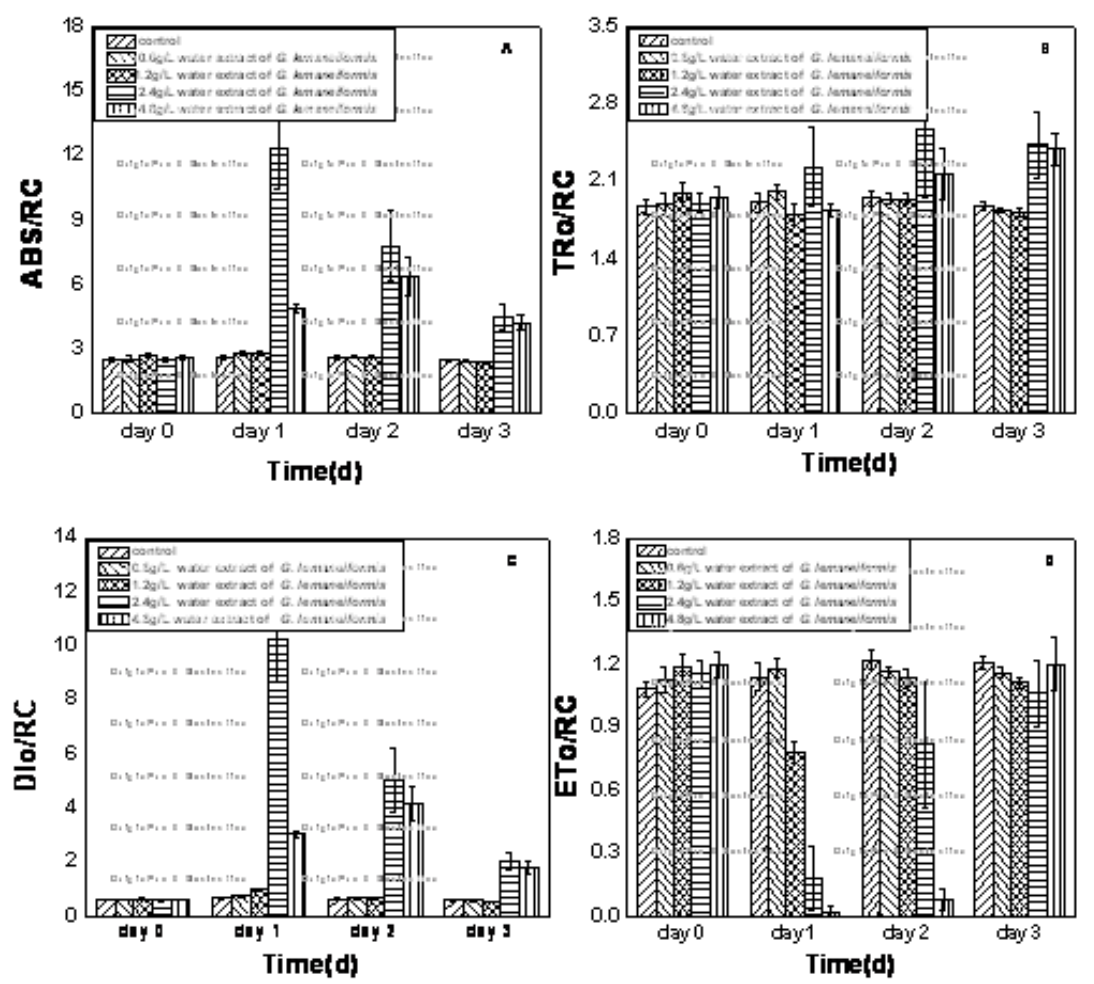

Fig.4. Specific energy fluxes per RC of S. trochoidea cultured with different concentrations of the water extract of G. lemaneiformis
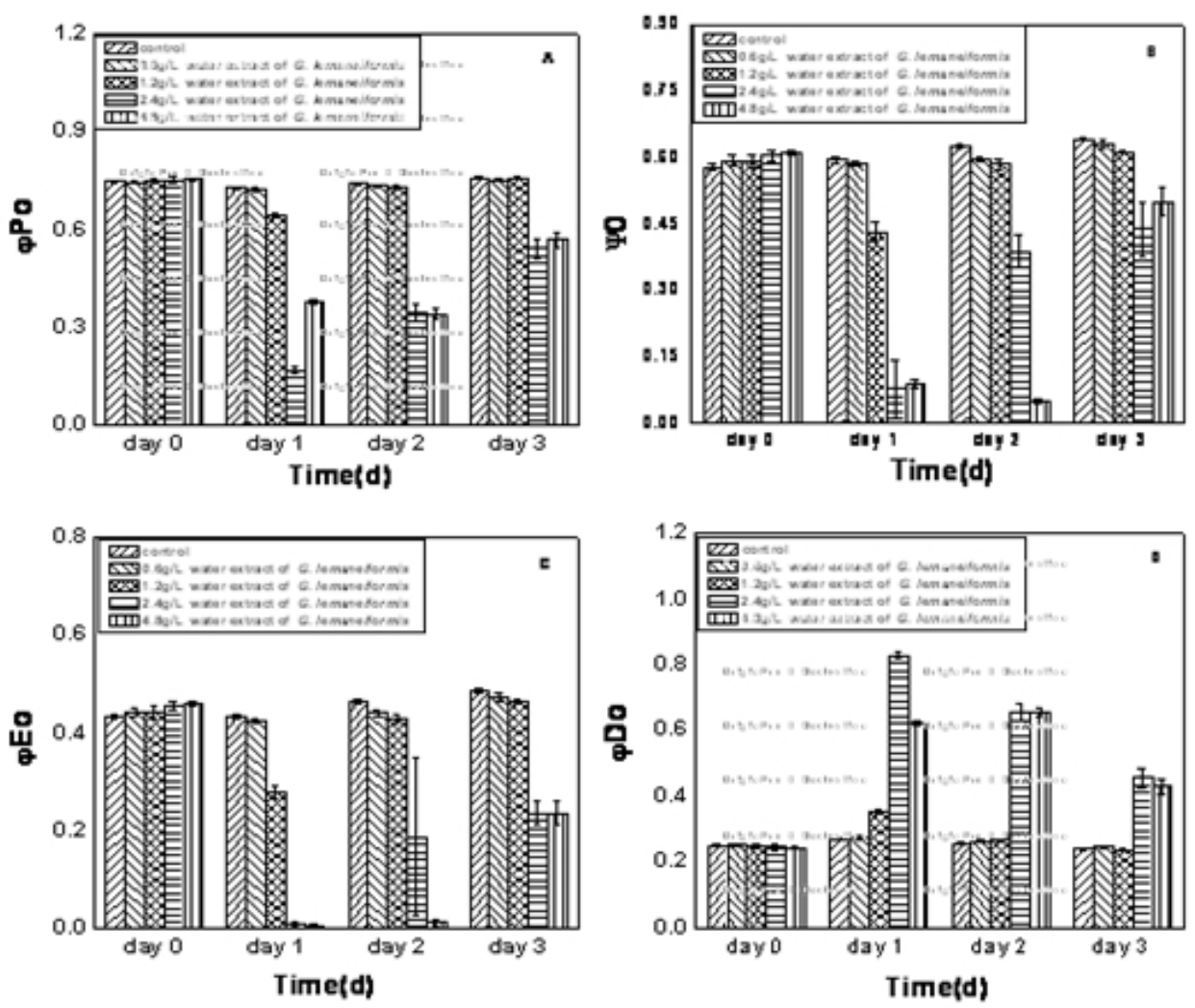

Fig.5. Quantum yield of $S$. trochoidea cultured with different concentrations of the water extract of $G$. lemaneiformis 

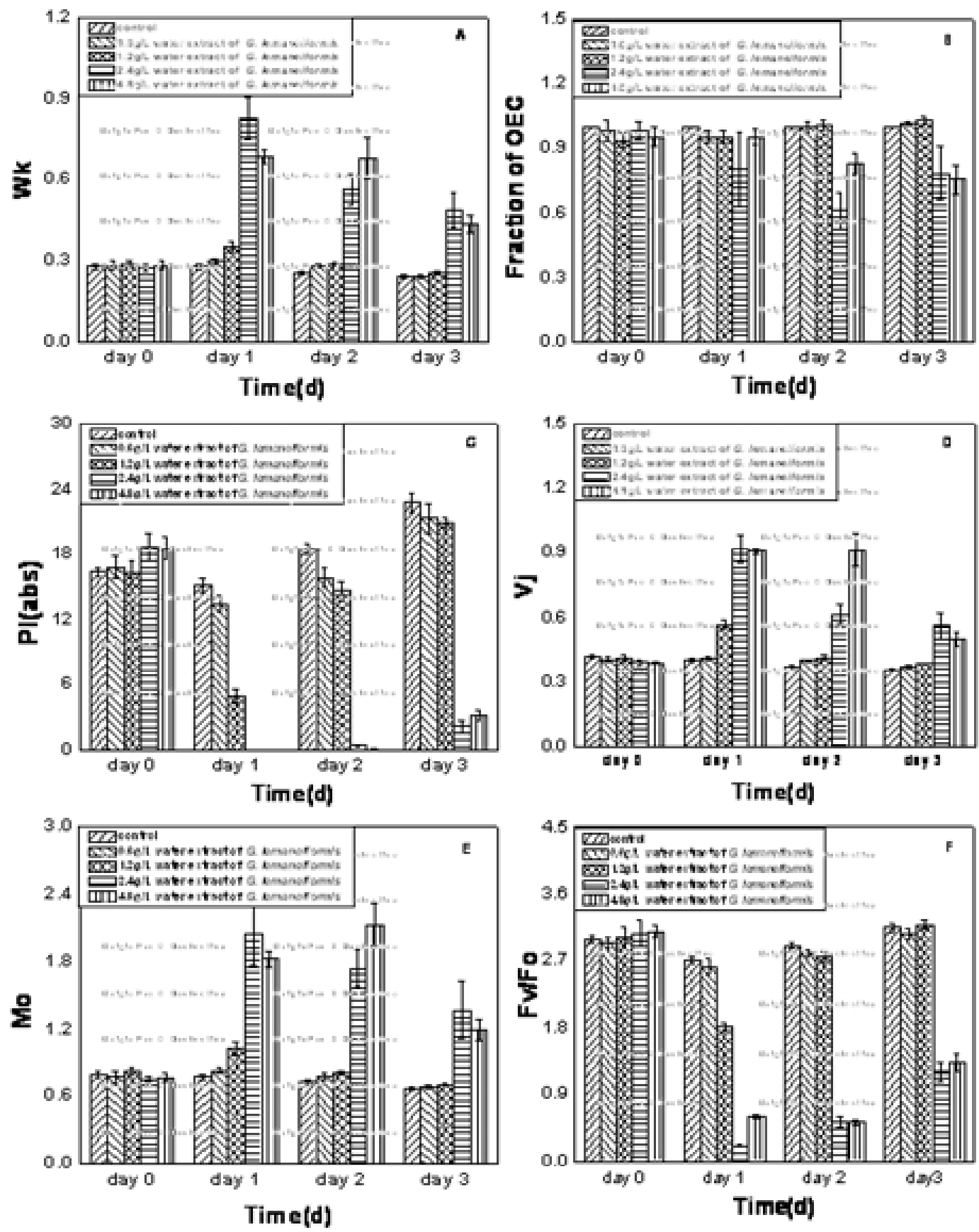

Fig.6. JIP-test parameters of $S$. trochoidea cultured with different concentrations of the water extract of G. lemaneiformis

The same concentration-dependent inhibition patterns were found in specific energy fluxes per RC (Fig. 4), Quantum yield (Fig. 5) and JIP-test parameters of S. trochoidea cultured with different concentrations of the water extract of G. Lemaneiformis (Fig. 6). The value of Wk, ABC/RC, $\mathrm{TRo} / \mathrm{RC}, \mathrm{DIo} / \mathrm{RC}, \mathrm{Vj}, \varphi \mathrm{Do}$ and $\mathrm{Mo}$ in $2.4 \mathrm{~g} / \mathrm{L}$ and $4.8 \mathrm{~g} / \mathrm{L}$ treatments was increased, while the value of fraction of OEC, $\varphi \mathrm{Po}, \mathrm{Fv} / \mathrm{Fo}, \mathrm{ETo} / \mathrm{RC}, \psi 0$, and $\varphi \mathrm{E}$ was decreased.

\section{Discussion}

Allelopathy is the biochemical interaction, both stimulatory and inhibitory, between primary producers or between primary producers and microorganisms ${ }^{36}$. When $S$. trochoidea was cultured with different concentration of water extraction of $G$. lemaneiformis, fresh thalli of G. lemaneiformis was cut into $0.3 \mathrm{~cm} \times 0.3 \mathrm{~cm}$ fragments to prevent the possible light shading, leading to the assumption that allelochemicals inhibited the microalga in this study. 
In the present study, chlorophyll a content of $S$. trochoidea was strongly suppressed by water extraction of $G$. lemaneiformis, and there was a clear concentration-dependent pattern, which was followed by $P_{\max }$ and $R d$, indicating the pigment complex in $S$. trochoidea was partial deactivation by the seaweed.

All oxygenic photosynthetic organisms investigated so far using show a polyphasic rise of of fluorescence transients during the first second of illumination, which are labelled as O-J-I-P $\mathrm{P}^{37}$. O-J-I-P is a useful, non-invasive tool for the study of the photosynthetic apparatus, and more specifically the behavior of photosystem $\mathrm{II}^{37,38}$. This O-J-I-P polyphasic transient has been found to change its shape according to changes in environmental conditions ${ }^{39,40}$. Quantitative analysis of recorded O-J-I-P Chl a fluorescence transients, by means of the JIP-test, result in the calculation of several biophysical parameters, which contain information about the fluxes of photons, excitons, electrons and further metabolic events at a given physiological state, and which can be used to quantify PSII function to different stressors (refer to ${ }^{37}$ for a review).

In our experiment, the O-J-I-P Chl a fluorescence transients, coupled with several biophysical parameters in $S$. trochoidea was depressed by the addition of water extraction of G. lemaneiformis. $\mathrm{ABS} / \mathrm{CS}_{0}$, absorption flux per excited cross-section of sample (at $\mathrm{t}=0$ ) was declined, indicating the quantity of antenna chlorophyll had decreased, so that not enough light was harvested to support the subsequent photochemical process. The concentration of the PSII reaction centers (RC/CS) decreased, indicating the density of active reaction center, i.e. photosynthetic units decreased, which reduced the photochemical transferring of harvested and excited photons. $\mathrm{ET}_{0} / \mathrm{CS}_{0}$, the electron transport flux per excited cross section (at $\mathrm{t}=0$ ) was reduced, suggesting that photosynthetic electron transport was blocked, indicating that photochemical flux of photons, excitons, electrons and further metabolic events in the photosystem of S. trochoidea were depressed, and finally the decline of growth in microalga (expressed as cell conentration).

In this study, the main photosynthetic inhibition targets by G. lemaneiformis water extraction on $S$. trochoidea were a decrease in the quantity and sieze of antenna chlorophyll (reflected by the decrease of, chlorophyll a, carotenoid concentration and $\mathrm{ABS} / \mathrm{CS}_{0}$ ), the number and trapping activity of active reaction centers $\left(\mathrm{RC} / \mathrm{CS}_{0}, \mathrm{TR}_{0} / \mathrm{CS}_{0}\right)$; the blocking of the electron transport chain (a decrease of $\left.\mathrm{ET}_{0} / \mathrm{CS}_{0}\right)$.

Tang and Gobler ${ }^{21}$ showed that the dried Ulva lactuca was equally or more potent than the fresh material, an observation consistent with the hypothesis that polyunsaturated fatty acids or organosulfur compounds are active allelopathic agents ${ }^{41}$, which were also observed in dried seaweed of G. lemaneiformis and G. tenuistipitat in our previous experiments ${ }^{42-44}$. Dithiolane and trithiane compounds isolated and identified from Characean species were also found to have allelopathic effects on epiphytic diatoms and other phytoplankton ${ }^{47} . \mathrm{Lu}^{45}$ isolated some secondary metabolites from G. lemaneiformis, such as glycolipid compounds, fatty acid compounds, amides, phenolic compounds and terpenoids. And by screening of allelochemicals, they found that the strongest allelopathy on the growth of the red tide alga, Skeletonema costatum was linoleic acid.

Our results show that water extraction of $G$. lemaneiformis strongly suppressed the photosynthesis of $S$. trochoidea culture, and that there was a clear concentration-dependent relationship reflected in a decreased pigment concentrations and O-J-I-P curve along with its specific parameters, such as the, $\mathrm{RC} / \mathrm{CS}_{0}, \mathrm{ABS} / \mathrm{CS}_{0}, \mathrm{TR}_{0} / \mathrm{CS}_{0}$ and $\mathrm{ET}_{0} / \mathrm{CS}_{0}$, revealing that the oxygen evolution complex, reaction centre and electron transport were damaged and/or inhibited, which finally resulted in the decrease of photosynthesis and growth in $S$. trochoidea. $\mathrm{Zhu}^{46}$ also found that allelopathic polyphenols, pyrogallic acid and gallic acid, isolated from submerged macrophyte Myriophyllum spicatum were the main factors responsible for the inhibition of PSII (from the oxygen-evolving complex to plastoquinone) and whole chain (from oxygen-evolving complex to the photooxidized chlorophyll) activities of Microcystis aeruginosa, a similar response in photosynthetic parameters was observed in our experiments. 


\section{Conclusions}

The results of this study suggest that water extraction of $G$. lemaneiformis had negative allelopathic effects on the growth and photosynthesis of $S$. trochoidea and could thus be a potential algicide to control and mitigate $S$. trochoidea blooms.

\section{Acknowledgements}

This work was financially supported by National Natural Science Foundation of China (31370476; 31000240), Science and Technology Planning Project of Guangdong Province (2014A020217005), Marine Fishery Science, Technology and Industrial Development Projects of Guangdong Province (A201401D03); Project on the Integration of Industry, Education and Research of Guangdong Province, China (2012B091100341); the Project of the Urban Management Bureau of Shenzhen (201510).

\section{References}

[1]D.M. Anderson, J.M. Burkholder, W.P. Cochlan, P.M. Glibert, C.J. Gobler, C.A. Heil, R. Kudela, M.L. Parsons, J.E.J. Renseli, D.W. Townsend, V.L Trainerk, G.A Vargo. Harmful algal blooms and eutrophication: examples of linkages from selected coastal regions of the United States. Harmful Algae 8 (2008), 39-53.

[2] J Heisler, P.M. Glibert, J.M. Burkholder, D.M. Anderson, W. Cochlan, W.C. Dennison, Q. Dortch, C.J. Gobler, C.A. Heil, E. Humphries, A. Lewitus, R. Magnien, H.G. Marshallm, K. Sellner, D.A. Stockwell, D.K. Stoecker and M. Suddleson: Eutrophication and harmful algal blooms: A scientific consensus. Harmful Algae 8 (2008), 3-13.

[3] D.M. Anderson: Approaches to monitoring, control and management of harmful algal blooms (HABs). Ocean \& coastal management 52 (2009), 342-347.

[4] G.M. Hallegraeff: Harmful algal blooms: a global overview. In Manual on Harmful Marine Microalgae, edtied by G.M. Hallegraeff and D.M. Anderson, UNESCO: Paris, France, (2003), p. 25-49.

[5] H.W. Paerl and V.J. Paul: Climate change: links to global expansion of harmful cyanobacteria. Water Research 46 (2012), 1349-1363.

[6] Y.O. Kim and M.S. Han: Seasonal relationships between cyst germination and vegetative population of Scrippsiella trochoidea (Dinophyceae). Mar. Ecol. Prog. Ser. 204 (2000), 111-118.

[7] G.L. Hold, E.A. Smith, M.S. Rappe, E.W. Maas, E.R.B. Moore, C. Stroempl, J.R.Stephen, J.I. Prosser, T.H. Birkbeck and S.Gallacher: Characterization of bacterial communities associated with toxic and non-toxic dinoflagellates: Alexandrium spp. and Scrippsiella trochoidea. FEMS Microbiol. Ecol. 37 (2001), 161-173.

[8] H.F. Gu, J. Sun, W.H.C.F. Kooistra and R.Y. Zeng: Phylogenetic position and morphology of thecae and cysts of Scrippsiella (Dinophyceae) species in the East China Sea. J. Phycol. 44 (2008), 478-494.

[9] Y. Wang and X.X. Tang: Interactions between Prorocentrum donghaiense Lu and Scrippsiella trochoidea (Stein) Loeblich III under laboratory culture. Harmful Algae 7 (2008), 65-75.

[10] J.H. Wang and J.Y. Wu: Occurrence and potential risks of harmful algal blooms in the East China Sea. Sci. Total Environ. 407 (2009), 4012-4021. 
[11].Y.Z. Tang and C.J. Gobler: Lethal effects of Northwest Atlantic Ocean isolates of the dinoflagellate, Scrippsiella trochoidea, on Eastern oyster (Crassostrea virginica) and Northern quahog (Mercenaria mercenaria) larvae. Mar. Biol. 159 (2012), 199-210.

[12] G.M. Hallegraeff: Harmful algal blooms in the Australian region. Mar. Pollut. Bull. 25 (1992), 186-190.

[13].X.M. Qin and J.Z. Zou: Studies on the effects of N, P, Fe-EDTA, Mn on the growth of a red tide dinoflagellate Scrippsiella trochoidea. Chin. Limnol. Oceanogr. 28 (1997), 594-598.

[14] T. Sugawara, K. Hamasaki, T. Toda, T. Kikuchi and S. Taguchi: Response of natural phytoplankton assemblages to solar ultraviolet radiation (UV-B) in the coastal water, Japan. Hydrobiologia 493 (2003), 17-26.

[15] X.C. Chen, H.N. Kong, S.B. He, D.Y. Wu, C.J. Li and X.C. Huang: Reducing harmful algae in raw water by light-shading. Process Biochem. 44 (2009), 357-360.

[16] X.X. Sun and J.K. Choi: Recovery and fate of three species of marine dinoflagellates after yellow clay flocculation. Hydrobiologia 519 (2004), 153-165.

[17] Y.J. Lee, J.K. Choi, E.K. Kim, S.H. Youn and E.J. Yang: Field experiments on mitigation of harmful algal blooms using a Sophorolipid-Yellow clay mixture and effects on marine plankton. Harmful Algae 7 (2008), 154-162.

[18] D.M. Anderson: Turning back the harmful red tide. Nature 388 (1997), 513-514.

[19] Y. Wang, B. Zhou and X.X. Tang: Effects of macroalga Gracilaria lemaneiformis on growth of Heterosigma akashiwo (Raphidophyceae). J. Appl. Phycol. 21 (2009), 375-385.

[20] Q. Jin and S.L. Dong: Comparative studies on the allelopathic effects of two different strains of Ulva pertusa on Heterosigma akashiwo and Alexandrium tamarense. J. Exp. Mar. Biol. Ecol. 293 (2003), 41-55.

[21] Y.Z. Tang and C.J. Gobler: The green macroalga,Ulva lactuca, inhibits the growth of seven common harmful algal bloom species via allelopathy. Harmful Algae 10 (2011), 480-488.

[22] R.J. Wang, L. Feng, X.X. Tang, J.H. Wang and S.L. Dong: Allelopathic growth inhibition of Heterosigma akashiwo by the three Ulva spcieces (Ulva Pertusa, Ulva Linza, Enteromorpha intestinalis) under laboratory conditions. Acta Oceanologica Sinica 31 (2012), 138-144.

[23] J.T. Xu and K.S. Gao: Growth, pigments, UV-absorbing compounds and agar yield of the economic red seaweed Gracilaria lemaneiformis (Rhodophyta) grown at different depths in the coastal waters of the South China Sea. J. Appl. Phycol. 20 (2008), 681-686.

[24] Y.Q. Zheng and K.S. Gao: Impacts of solar UV radiation on the photosynthesis, growth, and UV-absorbing compounds in Gracilaria lemaneiformis (Rhodophyta) grown at different nitrate concentrations. J. Phycol. 45 (2009), 314-323.

[25] C.C. Yeh, C.N. Tseng, J.I. Yang, H.W. Huang, Y. Fang, J.Y. Tang, F.R.Chang and H.W. Chang: Antiproliferation and Induction of Apoptosis in Ca9-22 Oral Cancer Cells by Ethanolic Extract of Gracilaria tenuistipitata. Molecules 17 (2012), 10916-10927.

[26] Z.H. Qi, H.M. Liu, B. Li, Y.Z. Mao, Z.J. Jiang, J.H. Zhang and J.G. Fang: Suitability of two seaweeds, Gracilaria lemaneiformis and Sargassum pallidum, as feed for the abalone Haliotis discus hannai Ino. Aquaculture 300 (2010), 189-193.

[27] Y. Wang, Z.M. Yu, X.X. Song, X.X. Tang and S.D. Zhang: Effects of macroalgae Ulva pertusa (Chlorophyta) and Gracilaria lemaneiformis (Rhodophyta) on growth of four species of bloom-forming dinoflagellates. Aquat. Bot. 86 (2007), 139-147. 
[28] C.R. Nan, H.Z. Zhang, S.Z. Lin, G.Q. Zhao and X.Y. Liu: Allelopathic effects of Ulva lactuca on selected species of harmful bloom-forming microalgae in laboratory cultures. Aquat. Bot. 89 (2008), 9-15.

[29] M.Y. Oh, S.B. Lee, D.H. Jin, Y.K. Hong and H.J. Jin: Isolation of algicidal compounds from the red alga Corallina pilulifera against red tide microalgae. J. Appl. Phycol. 22 (2010), 453-458.

[30] Y. Zhou, H. Yang, H. Hu, Y. Liu, Y.Z. Mao, H. Zhou, X.L. Xu, F.S. Zhang: Bioremediation potential of the macroalga Gracilaria lemaneiformis (Rhodophyta) integrated into fed fish culture in coastal waters of north China. Aquaculture 252 (2006), 264-276.

[31] S. Nakai, Y. Inoue, M. Hosomi and A. Murakami: Myriophyllum spicatum-released allelopathic polyphenols inhibiting growth of blue-green algae Microcystis aeruginosa. Water Res. 34 (2000), 3026-3032.

[32] J.H. Jeong, H.J. Jin, C.H. Sohn, K.H. Suh and Y.K. Hong: Algicidal activity of the seaweed Corallina pilulifera against red tide microalgae. J. Appl. Phycol. 12 (2000), 7-43.

[33] R.J. Strasser and A. Srivastava: Polyphasic chlorophyll $a$ fluorescence transient in plants and cyanobacteria. Photochemistry and Photobiology 61 (1995), 32-42.

[34] K.J. Appenroth, J. Stöckel, A. Srivastava and R.J. Strasser. Multiple effects of chromate on the photosynthetic apparatus of Spirodela polyrhiza as probedby OJIP chlorophyll $a$ fluorescence measurements. Environ. Pollut. 115 (2001), 49-64.

[35] A.R. Wellburn: The spectral determination of chlorophylls $a$ and $b$, as well as total carotenoids, using various solvents with spectrophotometers of different resolution. J. Plant Physiol. 144 (1994), 307-313.

[36] H. Molisch: Der Einfluss einer Pflanze auf die andere, Allelopathie. Fischer, Jena 1937, 106.

[37] R.J. Strasser, A. Srivastava, M. Tsimilli-Michael: The fluorescence transient as a tool to characterize and screen photosynthetic samples. In: Probing Photosynthesis: Mechanism, Regulation and Adaptation, edited by M. Yunus, U. Pathre and P. Mohanty, Taylor and Francis Press, London (2000), p. 445-483.

[38] R.J. Strasser, A. Srivastava and M. Tsimilli-Michael: Screening the vitality and photosynthetic activity of plants by fluorescence transient. In: Crop Improvement for Food Security, edited by R.K. Behl, M.S. Punia and B.P.S. Lather, SSARM Press, Hisar (1999), p. 72-115.

[39] A. Srivastava and R.J. Strasser: Constructive and destructive actions of light on the photosynthetic apparatus. J. Sci.Ind. Res. 56 (1997), 133-148.

[40] A.J. Clark, W. Landolt, J.B. Bucher, R.J. Strasser: Beech (Fagus sylvatica) response to ozone exposure assessed with a chlorophyll $a$ fluorescence performance index. Environ. Pollut. 109 (2000), 501-507.

[41] M.A. Alamsjah, S. Hirao, F. Ishibashi: Algicidal activity of polyunsaturated fatty acids derived from Ulva fasciata and U. pertusa (Ulvaceae, Chlorophyta) on phytoplankton. J. Appl. Phycol. 20 (2008), 713-720.

[42] C.P. Ye, M.C. Zhang, T. Ganapathy, Y. Zuo and Y.F. Yang: Photosynthtic inhibition on the microalga Dunaliella sallina (Chlorophyta) by the dried macroalga Gracilaria lemaneiformis (Rhodophyta). Biomedical Engineering and Biotechnology(iCBEB), 2012 International Conference on. Macao, China, 28-30 May 2012; IEEE: 2012, 400-404.

[43] C.P. Ye, M.C. Zhang and Y.F. Yang: Allelopathic effect of Gracilaria tenuistipitat (Rhodophyta) on the photosynthetic apparatus of Phaeodactylum tricornutum. Materials Science Forum 743 (2013), 725-731. 
[44] C.P. Ye and M.C. Zhang: Allelopathic inhibitory effects of the dried macroalga Ulva pertusa on the photosynthetic activities of red tide-causing microalga Skeletonema costatum. Advanced Materials Research 726 (2013), 29-34.

[45] H.M. Lu, H.H. Xie, Y.X. Gong, Q. Wang, Y.F. Yang: Secondary metabolites from the seaweed Gracilaria lemaneiformis and their allelopathic effects on Skeletonema costatum. Biochem. Syst. Ecol. 39 (2011), 397-400.

[46] J.Y. Zhu, B.Y. Liu, J. Wang, Y.N. Gao and Z.B. Wu: Study on the mechanism of allelopathic influence on cyanobacteria and chlorophytes by submerged macrophyte (Myriophyllum spicatum) and its secretion. Aquat. Toxicol. 98(2010), 196-203.

[47] S. Wium-Andersen, U. Anthoni, C. Christophersen and G. Houen: Allelopathic effects on phytoplankton by substances isolated from aquatic macrophytes (Charales). Oikos 39 (1982), 187-190.

[48] R.R.L. Guillard: Culture of phytoplankton for feeding marine invertebrates. In: Culture of Marine Animals, edited by W.L. Smith and M.H. Chanley, Plenum Press, New York (1975), p. 266 